\title{
Different perspectives in measuring processes in psychodynamic child psychotherapy
}

\section{Fredrik Odhammar, Geoff Goodman \& Gunnar Carlberg}

To cite this article: Fredrik Odhammar, Geoff Goodman \& Gunnar Carlberg (2018): Different perspectives in measuring processes in psychodynamic child psychotherapy, Journal of Child Psychotherapy, DOI: 10.1080/0075417X.2018.1539864

To link to this article: https://doi.org/10.1080/0075417X.2018.1539864

曲 Published online: 13 Nov 2018.

Submit your article to this journal $\widetilde{X}$

View Crossmark data $־$ 


\title{
Different perspectives in measuring processes in psychodynamic child psychotherapy
}

\author{
Fredrik Odhammar ${ }^{\mathrm{a}}$, Geoff Goodman ${ }^{\mathrm{b}}$ and Gunnar Carlberg \\ ${ }^{a}$ The Erica Foundation, Stockholm, Sweden; ${ }^{b}$ Long Island University, New York, USA
}

\begin{abstract}
The aim of this study was to explore how different measurements can contribute to understanding processes of change in psychodynamic child psychotherapy. The Child Psychotherapy Q-Set (CPQ) was compared with the child psychotherapist's description of the psychotherapy process, systematically collected every three months during therapy, and with the Feeling Word Checklist-24 (FWC-24) completed after each session. The aim was also to examine how these three different measurements together could describe change over time and how they were mirrored in the relationship between child and psychotherapist. The following questions were formulated: (1) What interaction structures can be identified with the CPQ? (2) How does the therapist describe the process in psychotherapy and how do therapists' feelings appear using the FWC-24? (3) How do the different measurements enrich one another and contribute to the understanding of the psychotherapeutic process? (4) How can the therapy be described compared to a hypothetical psychodynamic child psychotherapy prototype session? A videotaped child psychotherapy was analysed in its entirety. The CPQ provided a picture of the psychotherapist's and the child's actions and interactions, which complemented the subjective image of the psychotherapist when filling out questionnaires and the FWC-24. Analyses of the interaction between the child and the psychotherapist indicated the importance of creating a supportive and secure environment to achieve a feeling of psychological closeness, before working with the child's problems. The analysis of the therapy highlights the importance of the psychotherapist's meta-competence, i.e., overarching competencies that psychotherapists need to use to guide any intervention, what interventions to use, and when they are suitable.
\end{abstract}

\section{KEYWORDS}

Child psychodynamic therapy; Child Psychotherapy Q-Set; interaction structures; Feeling Word Checklist; single case study; process research

\section{Introduction}

Process factors in child psychodynamic therapy (PDT), playing a key role in psychotherapeutic interactions and therapeutic change, have not yet been satisfactorily identified (Midgley \& Kennedy, 2011). This is due to research having mostly focused on what kind of psychotherapy would give good results for different forms of mental health problems. Studies on psychotherapy process have contributed to a deep understanding of process and outcome, but tend to be too broad to identify specific active elements in individual therapy (Jones, 2000). Therefore, there is a need 
to analyse therapeutic interventions in the unique interaction between psychotherapist and child, in order to identify factors of change (Kazdin, 2009; Midgley, 2007).

\section{Child Psychotherapy Q-Set}

A way of examining process factors is the Child Psychotherapy Q-Set (CPQ), an instrument developed to describe therapeutic processes in child psychotherapy for children from 3 to 13 years of age (Schneider \& Jones, 2004). This method allows researchers to capture the complex interaction between psychotherapist and child in individual child psychotherapy (Schneider, Midgley, \& Duncan, 2010). The CPQ can identify patterns in psychotherapy process and similarities between different psychotherapeutic procedures and give a description of the interaction between child and therapist in a clinically descriptive language using relevant terminology (Bychkova, Hillman, Midgley, \& Schneider, 2011). Through rating whole sessions and comparing different sessions within the same treatment, continuity and development in therapeutic process are examined. Data can be used in comparative analyses of different phases in psychotherapy or between separate psychotherapies. With the CPQ, interaction structures can be measured, offering a way of operationalising aspects of interaction that may be central to change and fluctuation in a specific psychotherapy:

It [the CPQ] has even helped researchers describe the unique, ideographic and idiosyncratic processes occurring within individual dyads of therapists and patients [...] which many believe lie at the very heart of therapeutic action.

(Ablon, Levy, \& Smith-Hansen, 2011, p. 15)

The CPQ can be used to make comparisons between actual child psychotherapy treatments and how practice is conceptualised from a specific theoretical perspective. Goodman, Midgley, and Schneider (2016) examined how experienced psychotherapists from different perspectives of psychotherapy described hypothetical prototype sessions using the CPQ. Schneider, Pruetzel-Thomas, and Midgley (2009) found child therapists with a psychodynamic orientation used to help the child to elaborate and verbalise their feelings, whereas in cognitive behavioural therapy (CBT) the therapist focused on desirable behaviours, aiming to change the child's cognitive distortions. The CPQ items suggested as being most characteristic were, to a certain extent, common for the hypothetical prototype sessions in different theoretical perspectives. These included reflective functioning (Fonagy, Steele, Moran, Steel, \& Higgit, 1991), which appeared to be a process factor common to several treatment perspectives. Psychotherapists' interventions in actual child psychotherapy have proved to be different than hypothetical prototype sessions due to different conditions and circumstances in psychotherapy (Gastaud, Carvalho, Goodman, \& Ramires, 2015; Pruetzel-Thomas, 2006). For example, different interaction structures were identified in one and the same psychotherapy (Goodman \& Athey-Lloyd, 2011). Schneider et al. (2010) relate that different kinds of behaviour in children can call forth a certain type of technique from the therapist, within the same form of psychotherapy.

One other way of acquiring an image that covers the psychotherapeutic process is to let the psychotherapist express their subjective experience in different ways. Video recordings of therapy have shifted the focus towards a third-party perspective, avoiding previous bias but marginalising therapists' first-hand reports of the process (Schröder, 
Orlinsky, Rønnestad, \& Willutzki, 2015). In a questionnaire, the psychotherapist can express his/her subjective view of the course of the psychotherapy sessions. Di Lorenzo, Maggiolini, and Suigo (2015) found that questionnaires provided meaningful information about the psychotherapy process, when describing psychotherapists' practice with adolescents in psychodynamic psychotherapy and its similarities and differences with other adolescent psychotherapeutic approaches. They also aimed at analysing typical therapist responses to adolescent patients.

\title{
Feeling Word Checklist-24
}

The Feeling Word Checklist-24 (FWC-24) is a self-rating tool that allows the psychotherapist to rate, after each session, to what degree he or she has experienced various feelings during the therapeutic interaction (Holmqvist, 2001). The psychotherapist's emotional response is an important aspect of a psychotherapy session, which sheds light on the relationship between patient and psychotherapist (Dahl, Røssberg, Bøgwald, Gabbard, \& Høglend, 2012). The therapist's feelings may also influence how the therapist delivers the specific techniques or how the patient perceives the intervention (Dahl et al., 2014). Therapists' own emotional reactions may also be considered as important information regarding ongoing processes in psychodynamic psychotherapy. The therapist's reported feelings may be affected by their personality, self-image and emotional style, as well as by their pattern of reacting emotionally to others (Mitchell, Aron, Harris, \& Suchet, 1999). A specific patient may evoke specific feelings in the therapist, or the patient's previous relationships may be repeated in the therapeutic relationship. The therapist's feelings could also emerge from the unique interaction between the patient and the therapist:

The meeting of patient and therapist results in the creation of shared feelings and fantasies that are partly independent of previous patterns, and a shared "life" in the therapeutic relationship is created.

(Holmqvist \& Armelius, 1996, p. 76)

\begin{abstract}
Aim
The aim of this study was to explore how different measurements can contribute to understanding processes in psychodynamic child psychotherapy. The Child Psychotherapy Q-Set (Schneider \& Jones, 2004) was systematically compared with the child psychotherapist's description of the psychotherapy process and the Feeling Word Checklist-24 (Holmqvist, 2001). The aim was also to examine how these three different measurements together could describe processes over time and how they are mirrored in the relation between child and psychotherapist (Bychkova et al., 2011; Goodman \& Athey-Lloyd, 2011; Schneider et al., 2010). To explore the above, the following questions were formulated:
\end{abstract}

- What interaction structures can be identified through the CPQ?

- How does the therapist describe the process in psychotherapy and how do the therapists' feelings appear using the FWC-24? 
- How do the different descriptions - CPQ, the psychotherapists' descriptions of the psychotherapy and FWC-24 - enrich each other and contribute to the understanding of the psychotherapeutic process?

- How can the therapy be described compared to a hypothetical psychodynamic child psychotherapy prototype session?

\section{Method}

Earlier systematic process studies have generally been based on relatively few sessions of entire psychodynamic child psychotherapies. Hence, there is a need for examining the process in complete psychotherapy treatments, where all sessions of the therapy are included. To answer this study's research questions, a longitudinal repeated-measures systematic case study was performed, examining all the sessions in a videotaped child psychotherapy within routine child psychiatry care.

The present study was part of the Erica Process and Outcome Study (EPOS) at the Erica Foundation in Stockholm (Carlberg, 2010; Odhammar, Sundin, Jonson, \& Carlberg, 2011). To attain a high degree of external validity, a naturalistic approach was used in EPOS with close attention paid to clinical context with children found in everyday clinical practice. Child psychiatric assessment was conducted before and after psychotherapy. The assessment included the DSM-IV and Children's Global Assessment Scale (CGAS; Shaffer et al., 1983), which is a global scale used in child and adolescent psychiatry. Functioning at home, school and with peers is rated on a scale from 1 to 100 (Lundh, Kowalski, Sundberg, Gumpert, \& Landén, 2010). The Strength and Difficulties Questionnaire (SDQ; Goodman, 1997) was completed by parents and school. These data provided a picture of the child's global functioning, psychiatric symptoms, relational difficulties, and how severe and problematic those around the child felt the problems were.

\section{Participants}

Benjamin was a boy who had just turned eight when psychotherapy started. Benjamin had frequent angry outbursts and could then throw things, hit himself, and become violent towards peers and adults. He had a negative self-image, which made him behave like a 'know it all person' in situations where he felt fragile. Benjamin was easily worried and tried to control situations that he experienced as creating anxiety through controlling others. He distanced himself from fear and threatening events. Benjamin would often worry about unexpected events.

The psychotherapist was an experienced female psychologist and licensed psychotherapist with formal training in psychodynamic child and adolescent psychotherapy, with more than 20 years of experience in Child \& Adolescent Mental Health Services (CAMHS). The therapy was conducted as a part of routine clinical practice in a CAMHS in one of the larger cities in Sweden.

Benjamin was referred by his mother, who was worried about his violent outbursts. He was offered an assessment for PDT. The assessment, conducted by the therapist and a child psychiatrist, concluded that Benjamin met the DSM-IV criteria for Generalised Anxiety Disorder and scored CGAS 55 with regard to functioning level, which in the 
CGAS manual is defined as 'Variable functioning with sporadic difficulties or symptoms in several but not all social areas' (Shaffer et al., 1983). On the SDQ, Benjamin scored 13 on Problems/Difficulties and 6 on the Impact Score. The Impact Score refers to the parent's view of the extent to which the child's difficulties put a burden on the parent or the family as a whole (Goodman, 1997). A score greater than 1 counts as the cut-off indicating problematic behaviour.

Before therapy started, the child psychotherapist completed a questionnaire were she indicated the following goals when answering the question: Describe the three most important goals regarding this therapy. These three goals were treated as equal without reference to any internal order of preference (Odhammar \& Carlberg, 2015).

(1) Give Benjamin access to positive and self-asserting strength.

(2) Develop Benjamin's self-esteem.

(3) Increase Benjamin's ability to cope and deal with worry and anxiety.

The parallel fortnightly parent work sessions, conducted by a trained parental psychotherapist, focused on how to understand and respond to Benjamin's outbursts and oppositional behaviour. Benjamin's separation-anxiety and emotional distress, as well as the parent's need to be listened to were discussed.

\section{Ethical considerations}

The study was approved by the local ethics committee at Karolinska Institutet. The parents gave their written approval of informed consent. The child was asked verbally by the psychotherapist of his consent on videotaping the sessions. For the purpose of this study, the psychotherapy has been video-recorded in its entirety and the patient's confidentiality and anonymity have been protected by excluding any account of the psychotherapy's actual content, such as verbal communication and themes in playing. Information that would make identification possible has been changed without changing the meaning of the content. The researchers did not have any previous knowledge of the psychotherapy in this study.

\section{Measures}

(1) The CPQ consists of 100 items. Three types of items describe the session: (1) the child's feelings, behaviour or experience, (2) the psychotherapist's actions and attitudes, and (3) the emotional climate and the character of the interaction. The items above are sorted into nine categories from attitudes, experiences and behaviour being most to least characteristic with regards to the understanding of the psychotherapy session as a whole (for more information about the rating procedure see; Schneider \& Jones, 2004).

(2) Data questionnaires were completed by the child psychotherapist. The questions asked were formulated: (1) Describe important themes during the time period. (2) How did the child express himself during the time period? (3) Describe the development of the contact between you and the child during the time period. (4) Describe changes during the time period. 
(3) FWC-24 is a 24-item self-report measure in which therapists rate their emotional responses during a session on a 4-point scales ranging from 0 (not at all) to 3 (very much) (Holmqvist, 2001).

\section{Procedure}

Benjamin's psychodynamic child psychotherapy treatment was videotaped in its entirety. The psychotherapy was carried out at a CAMHS in Sweden during 15 months and comprised 42 sessions. The once weekly psychotherapy sessions were 45 minutes long. The sessions took place in a special child psychotherapy room with various play materials that the child could use to express himself such as a sandbox with toys to match, glove puppets, artist's colours, play-doh and various board games. Parallel parent work sessions were offered by a parental psychotherapist fortnightly. Every three months, questionnaires were distributed asking about the psychotherapist's stated goals and experienced goal fulfilment as well as the psychotherapist's description of the psychotherapy process and changes in the child. The FWC-24 was filled out by the psychotherapist after each therapy session.

\section{Data processing and data analysis}

Interaction in the psychotherapy sessions was rated in random order with the CPQ in 40 sessions by the first author according to the CPQ manual (Schneider \& Jones, 2004). Two sessions (11 and 13) were dropped since technical problems with the recording made CPQ coding impossible. Interrater reliability was secured by an independent rater who was trained in CPQ rating to achieve consistency $(\mathrm{ICC}=.70)$. High interrater reliability was achieved in rating 10 randomly selected sessions (ICC $=.72$; range: .69-.78), which included $25 \%$ of the material. The independent rater had no prior knowledge concerning the therapy, that is Benjamins's problem or diagnosis or information concerning the research questions. In the analysis of the therapist's subjective description, written down every month, the intention was to come as close as possible to the therapist's own descriptions.

Initially, the 10 most and least characteristic CPQ items during the entire psychotherapy were analysed (Tables 1 and 2). These items were calculated by summing the ratings of all 40 sessions, dividing by 40 , and rank-ordering the means. This was done to capture a common tone in the psychotherapy (Goodman \& Athey-Lloyd, 2011).

Table 1. The 10 items rated as most characteristic in the examined psychotherapy.



Mean values for the entire therapy, scale $1-9$. 
Table 2. The 10 items rated as least characteristic in the examined psychotherapy.

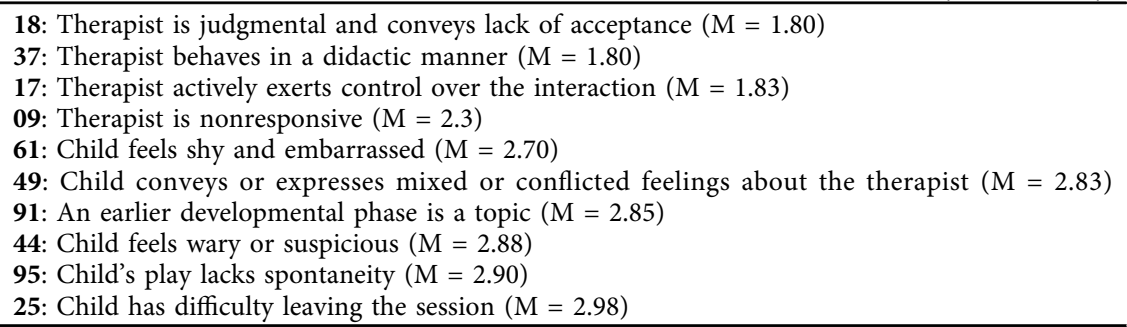

25: Child has difficulty leaving the session $(\mathrm{M}=2.98)$

Mean values for the entire therapy, scale $1-9$.

Thereafter, a principal component analysis with varimax rotation was conducted to find specific interaction structures (Table 3). Correlations between session number and interaction structures were performed. A within-subjects MANOVA ${ }^{1}$ followed by pairwise statistical comparisons on the four CPQ interaction structures was conducted to determine which interaction structures predominated. Another way of describing the psychotherapy is to compare it to the most significant CPQ items in the prototype for psychodynamic child psychotherapy that was created from ratings carried out by experienced child psychotherapists (Goodman et al., 2016). Session CPQ ratings were correlated with each of the three prototypes (PDT adherence, CBT adherence and reflective functioning, RF adherence) to create prototype correlation scores, which indicate the degree to which session adhered to a prototype, derived after a $\mathrm{Q}$-factor analysis with varimax rotation of ratings by experienced psychotherapists with different theoretical orientations (Goodman et al., 2016). The four interaction structures and the three prototypes were intercorrelated. A within-subjects MANOVA followed by pairwise statistical comparisons on the three CPQ prototypes was conducted to determine which prototype adherence predominated.

Next, the questionnaires where the child psychotherapist described her experience of the therapy process every three months, as well as at the end (consisting of five time-points in total) were analysed using qualitative content analysis (Graneheim \& Lundman, 2004). The child therapist's answers in the questionnaires were read through several times to get an overall picture of the therapist's view of the interaction between her and the child. The content was categorised using the same three perspectives found in coding the CPQ (the boy's behaviour, therapist's actions and the interaction between) which constituted the units of analysis. Thereafter therapist's descriptions were placed within the five time-points.

Finally, the child psychotherapist's FWC lists were analysed. A principal components analysis with varimax rotation was completed to calculate six FWC factors (Table 4). To conclude, correlation analyses between the calculated FWC factors and the CPQ interaction structures and thereafter the three prototypes (PDT, CBT and RF) were conducted. 
Table 3. Interaction structures The Child Psychotherapy Q-Set.

INTERACTION STRUCTURE SUPPORTIVE

54 Child is clear and organised in verbal expression.

77 Therapist's interaction with child is sensitive to the child's level of development. $\quad .702$

82 Therapist helps child manage feelings.

72 Child is active. $\quad .619$

62 Therapist points out a recurrent theme in the child's experience or conduct. $\quad-.605$

29 The quality of child's play $\quad .583$

79 Therapist comments on changes in child's mood or affect.is fluid, absorbed [vs. fragmented, $\quad-.558$ sporadic].

34 Child blames others, or external forces, for difficulties.

47 When the interaction with the child is difficult, the therapist accommodates the child.

100 Therapist draws connections between the therapeutic relationship and other relationship

\section{Therapist actively exerts control over the interaction (e.g., structuring, introducing new topics).}

07 Child is anxious and tense [vs. calm and relaxed].

Child is curious.

Sexual feelings or thoughts emerge.

16 There is discussion or evidence of bodily functions (e.g., bowel movements).

86 Therapist is confident, self-assured [vs. uncertain or unsure].

56 Child is distant from his or her feelings. $\quad .510$

24 Therapist's emotional conflicts intrude into the relationship. $\quad .508$

76 Therapist makes links between child's feelings and experience. $\quad-.505$

45 Therapist tolerates child's strong affect or impulses.

49 Child conveys or expresses mixed or conflicted feelings about the therapist. -.482

26 Child is socially misattuned or inappropriate. -.444

74 Humour is used. $\quad .438$

59 Child feels inadequate and inferior [vs. effective and superior].

38 Therapist and child demonstrate a shared vocabulary or understanding when referring to events or .402 feelings.

66 Therapist is directly reassuring.

44 Child feels wary or suspicious [vs. trusting and secure].

INTERACTION STRUCTURE WORKING WITH PROBLEMS

13 Child is animated or excited.

01 Child expresses negative feelings (e.g., criticism, hostility) towards therapist [vs. expresses approval or admiration].

Child expresses fears of being punished or threatened.

Child's aspirations or ambitions are themes.

88 Material of the hour is meaningful and relevant to child's conflicts. -.623

95 Child's play lacks spontaneity. $\quad .602$

23 Therapy session has a specific focus or theme. $\quad .572$

81 Therapist emphasises feelings to help child experience them more deeply. -.567

67 Therapist interprets warded-off or unconscious wishes, feelings, or ideas. $\quad-.555$

65 Therapist clarifies, restates, or rephrases child's communication. $\quad-.546$ 
Table 3. (Continued).

\begin{tabular}{llr}
\hline 83 & Child is demanding. & .527 \\
99 & Therapist offers help or guidance. & .482 \\
32 & Child achieves a new understanding or insight. & .465 \\
28 & Therapist accurately perceives the therapeutic process. & -.464 \\
66 & Therapist is directly reassuring. & .462 \\
47 & When the interaction with the child is difficult, the therapist accommodates the child. & .460 \\
93 & Therapist is neutral. & -.459 \\
06 & Therapist is sensitive to the child's feelings. & -.450 \\
09 & Therapist is nonresponsive [vs. affectively engaged]. & .447 \\
62 & Therapist points out a recurrent theme in the child's experience or conduct. & -.433 \\
57 & Therapist attempts to modify distortions in child's beliefs. & .429 \\
97 & Therapist emphasises verbalisation of internal states and affects. & -.417 \\
46 & Therapist interprets the meaning of child's play. & -.412 \\
24 & Therapist's emotional conflicts intrude into the relationship. & .409 \\
64 & Child draws therapist into play. & -.407 \\
& INTERACTION STRUCTURE STRUCTURED CLOSENESS & \\
10 & Child seeks greater intimacy with the therapist. & .572 \\
69 & Child's current or recent life situation is emphasised. & -.557 \\
42 & Child ignores or rejects therapist's comments and observations. & -.564 \\
44 & Child feels wary or suspicious [vs. trusting and secure]. & -.553 \\
36 & Therapist points out child's use of defences. & -.514 \\
91 & An earlier developmental phase is a topic. & .510 \\
27 & There is a focus on helping the child plan behaviour outside the session. & .501 \\
96 & Child's parents are a topic of discussion. & -.481 \\
70 & Child struggles to control feelings or impulses. & -.476 \\
41 & Child does not feel understood by the therapist. & -.444 \\
99 & Therapist offers help or guidance. \\
29 & The quality of child's play is fluid, absorbed [vs. fragmented, sporadic]. \\
04 & There is discussion of why child is in therapy. & .426 \\
\hline & .422 \\
\hline
\end{tabular}

Table 4. Factors Feeling Word Checklist.

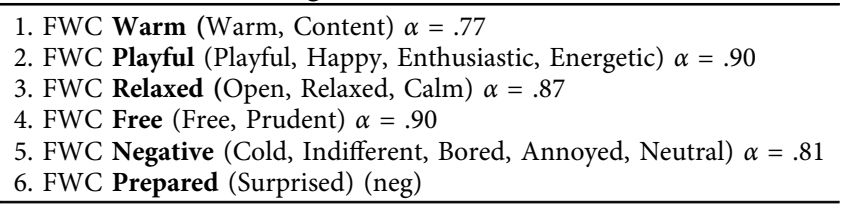

\section{Results}

\section{Child Psychotherapy Q-Set ratings}

Firstly, the 10 most and least characteristic CPQ items during the entire psychotherapy were identified (Tables 1 and 2). The child can be described as spontaneous and active. $\mathrm{He}$ is mostly positive about coming to therapy, he likes and trusts the psychotherapist. The boy's communication of his affects, both positive and negative, varies a lot during the sessions. The therapy tends to focus more on the present than on earlier phases of the child's life. The psychotherapist acts in accordance with Benjamin's stage of development, is accepting and has a non-judgmental attitude. She is open to the child's emotions and helps him to experience them more deeply through affective attunement. The psychotherapist lets the child lead the interaction and does not tend to teach the child strategies to overcome his problems. 


\section{Interaction structures in Benjamin's psychotherapy}

Thereafter, four interaction structures were calculated. These explained $34 \%$ of the total variance (Table 3).

Interaction structure 1: Supportive (Cronbach's $\alpha=.90$ )

The child is active but does not work with his psychological problems. He distances himself from his feelings. The psychotherapist is flexible with a contact-building and supportive approach, in a way that is not perceived as demanding. The therapist tolerates the child's strong emotions and impulses. The therapist does not comment upon changes in the child's emotional state.

\section{Interaction structure 2: Working with Problems (Cronbach's $\alpha=.87$ )}

The child shows his fears and sadness. Themes that are problematic are addressed. The therapist is active, clarifies and intervenes. The problem manifests itself in the relationship between the child and the psychotherapist. The child's feelings and experiences are linked to past situations. The therapy relationship is discussed.

\section{Interaction structure 3: Power Struggle (Cronbach's $\alpha=.83$ )}

The interaction is characterised by the child being demanding and not letting the psychotherapist come close and the child's problems are avoided. The therapist takes a more didactic rather than interpretive role and does not see the therapeutic process clearly. The therapist does not clarify or interpret the child's internal states and feelings.

Interaction structure 4: Structured Closeness (Cronbach's $\alpha=.75$ )

The interaction is characterised by structured closeness between the child and the psychotherapist. The child listens and trusts the therapist, feels confident and understood by the therapist. The child seeks closeness with the therapist. The therapist gives advice and helps the child to plan behaviour outside sessions.

The within-subjects MANOVA analyses indicated that Supportive was more prominent than Working with Problems and Structured Closeness, which were in turn more prominent than Power Struggle. In other words, the therapist's support of this child was the predominant interaction structure over the treatment course. Structured Closeness was negatively correlated with session number $(r=-.43, p=.005)$, indicating decreasing structured closeness between child and therapist during psychotherapy over the treatment course.

\section{Questionnaires}

The child therapist described the psychotherapy with Benjamin through questionnaires completed every three months and after the last session. These are summarised below:

\section{Time-point 1: 3 months}

The first months were dominated by a struggle with coming to therapy. Benjamin struggles to leave his parent in the waiting room. The psychotherapist works to create a framework for the psychotherapy and to establish the working alliance between the two of them. Benjamin has difficulties coping with uncertainty, wants 
control over the situation, and there are negotiations on what rules apply to the sessions. The psychotherapist clarifies and verbalises feelings that are aroused in Benjamin in relation to her. Benjamin does not express his problems or difficult feelings in words.

\section{Time-point 2: 6 months}

This phase of the treatment is marked by the creation of a deeper contact between Benjamin and the psychotherapist. Benjamin shows ambivalence towards the therapy. Benjamin's difficulties relating to separation appear. A clear theme is Benjamin's worry about leaving his parents. Benjamin can now express sadness verbally but holds himself together since he does not dare to be sad in front of the psychotherapist. The psychotherapist is more active and at ease in her contact with Benjamin.

\section{Time-point 3: 9 months}

The contact between the therapist and Benjamin becomes more trusting, and Benjamin is less tense. The content of therapy is primarily competition. Benjamin cannot stand losing at games, and he actively takes control. There is a focus on winning fairly, in contrast to cheating and grabbing. Benjamin feels bad when he fails, and the psychotherapist tries to get him to lighten his heavy demands on himself. The psychotherapist emphasises, illustrates and verbalises thoughts and feelings, especially concerning their relationship. Benjamin is becoming able to put into words difficult feelings and is more talkative about what goes on outside therapy. The therapist feels more relaxed about the alliance.

\section{Time-point 4: 12 months}

Benjamin is able to symbolically express through play his worry and anxiety about uncertainty. Benjamin's fears that important people will disappear and that he will get hurt are processed. Benjamin enjoys being admired and likes to show off. A relationship with increasing focus on cooperation emerges. A better working alliance is created, where the therapist can be less active and can follow Benjamin's lead more.

\section{Time-point 5: 15 months (the therapy ended after 15 months)}

Benjamin dares to confide in the therapist and expresses his fantasies and fears. Benjamin shows more positive self-esteem. A deepened contact between Benjamin and the psychotherapist is brought about, and Benjamin explores the relationship between them. Benjamin's fears of injuries and catastrophes emerge in the play material. Benjamin also shows, through his play, aggressiveness and destructiveness on one hand, and weakness and fragility on the other. For the first time, Benjamin puts into words his anger, and he actively seeks the therapist's assistance to explore and process his feelings of aggression.

\section{Relationships between the feeling words checklist, time, and the interaction structures}

The FWC analysis yielded six factors explaining $79 \%$ of the variance (Table 4). 
Three of the FWC factors were positively correlated with session number and thus increased with time: FWC Free $(r=.47, p=.002)$, FWC Warm $(r=.35, p=.027)$, and FWC Relaxed ( $r=.33, p=.038)$. In other words, the therapist felt freer, warmer, and relaxed over the treatment course. No negative correlations were found.

$C P Q$ interaction structure Supportive was significantly positively correlated with FWC Free $(r=.54, p=.000)$ and FWC Playful $(r=.46, p=.003)$. Working with Problems was significantly negatively correlated with FWC Free $(r=-.43, p=.006)$, FWC Playful $(r=-.42, p=.007)$, FWC Relaxed $(r=-.34, p=.034)$, and FWC Warm $(r=-.33, p=.039)$. In other words, the more free and playful the therapist felt in each session, the more supportive the therapist was towards the child. The less free, playful, relaxed, and warm the therapist felt in each session, the more the therapist focused on working with the child's problems. The other two interaction structures were not significantly correlated with any of the FWC factors.

\section{The psychotherapist's subjective descriptions compared with the CPQ interaction structures}

The psychotherapist's subjective description after three months corresponds in many ways to the CPQ interaction structures Power Struggle and Supportive. There is a struggle concerning Benjamin coming to therapy, where the psychotherapist supports Benjamin in daring to concentrate on psychotherapy. The psychotherapist works on creating a framework for the psychotherapy and the working alliance between the two of them. After six months, the description in many ways corresponds to the interaction structure Structured Closeness. The therapist describes a close emotional contact that slowly emerges, with feelings of intersubjectivity. Benjamin and the psychotherapist have come one step closer to one another, among other things due to the psychotherapist's understanding of why Benjamin did not want to come. After nine months, the therapist's description corresponds to Structured Closeness and Working with Problems. Benjamin begins to approach his worries and his feelings of littleness. It gets easier for the therapist to put Benjamin's sadness and worries about separation into words. The psychotherapist emphasises, clarifies and verbalises thoughts and feelings, especially concerning their relationship. There is also a wish by Benjamin to learn to know the therapist better on a more personal level:

B: Do you know someone named Anna?

T: Do you feel a bit curious..?

B: Ahh, you're so annoying! Do you have kids?

T: I am not going to answer certain questions. But, it is good that you ask. What do you think?

B: I want to know if you play video games, do you?

T: You can't really find that out either.

B: When will we end today?

T: In fifteen minutes. You do not like not getting answers. I understand that, and it seems strange to you that we have such a rule.

After 12-15 months, the description in many ways corresponds to the interaction structure Working with Problems. During this period, the work with Benjamin's selfesteem and trust in others and the surrounding world deepens. Benjamin can leave his 
omnipotent defence and experience what it is like to be little and weak. The therapist describes how Benjamin's trust in his own strength, and his ability to manage difficulties increases. Benjamin seems no longer as watchful and threatened by their close relationship, and it becomes important to him to share emotions with his psychotherapist.

\section{Comparison with prototype sessions}

Analysis with a within-subjects MANOVA indicated that PDT adherence and RF adherence were more prominent than CBT adherence. The PDT prototype was negatively correlated with Power Struggle $(r=-.83, p=.000)$. The CBT prototype was positively correlated with Structured Closeness $(r=.49, p=.001)$. The RF prototype was negatively correlated with Power Struggle $(r=-.71, p=.000)$. In other words, PDT process and RF process were the predominant prototypes used over the treatment course. The more the therapist and child engaged in a power struggle, the less adherent the therapist was to the PDT and RF process prototypes. The more the therapist engaged in structured closeness with the child, the more adherent the therapist was to the CBT process prototype.

The PDT prototype was negatively correlated with FWC Relaxed $(r=-.33$, $p=.036)$. The CBT prototype was also positively correlated with FWC Playful $(r=.44, p=.004)$ and negatively correlated with FWC Negative $(r=-.38$, $p=.015)$. In other words, the more relaxed the therapist felt in each session, the less adherent the therapist was to the PDT process prototype. The more playful and less negative the therapist felt in each session, the more adherent the therapist was to the CBT process prototype.

\section{Psychiatric assessment at the end of therapy}

Child psychiatric assessment after therapy showed that Benjamin did not meet criteria for any diagnosis, according to the DSM-IV (American Psychiatric Association, 2000). Benjamin was assessed as having a CGAS of 91, a SDQ Problems/Difficulties Score of 6, and Impact Score of 0. After completing the therapy, all three goals were fulfilled; (1) Give Benjamin access to positive and self-asserting strength; (2) Develop Benjamin's self-esteem; and (3) Increase Benjamin's ability to cope and deal with worry and anxiety.

At the end of therapy, the child psychotherapist related that Benjamin gained access to good self-assertive strength, which contributed to his feelings of being an independent individual, and to gaining an ideal of self that is commensurate with his age. His anxiety and worry decreased, which led to Benjamin's being better able to cope with separation from his parents. Benjamin had better impulse control and seldom became violent. In his everyday life, Benjamin also became considerate towards others and made more contact with friends. Benjamin worked more independently and showed more concentration in school. 


\section{Discussion}

This study indicates that different methods of understanding psychotherapy mirror this treatment in different ways. CPQ gives us an image of the psychotherapist's actions and the child's actions, as well as of the interaction between them, which complements the subjective image that the psychotherapist describes when filling out the questionnaires. When it comes to the psychotherapist's own description of psychotherapy, the development of therapy over time and goal fulfilment are more clearly perceived. The clear development of the therapy can be partially assumed to be coloured by the psychotherapist's own understanding of distinct stages in the process of psychotherapy. Statistically, interaction structure Structured Closeness decreased over time. The therapist's own description of a feeling of more psychological closeness increased over time. One explanation could be that through the structured closeness prominent in the beginning of therapy Benjamin could feel safer in the situation and come closer to the therapist psychologically. This was obvious in the countertransference of the therapist, captured in the description of the therapy in FWC.

Explicit conversations about goals and expectations have been described as an important part of the therapeutic alliance (Svendsen \& Hansen, 2008). In the psychotherapy investigated in the present study, very few conversations on why Benjamin needs psychotherapy, and what the goals of the therapy should be, took place. The therapist indirectly and metaphorically addressed goals in a way Benjamin could digest. An explicit discussion of treatment goals would probably not have reached Benjamin at this point.

The child psychiatric assessment at termination concluded that Benjamin has better global functioning ability and fewer relational and emotional difficulties. How can this improvement be understood from descriptions of the psychotherapy process? Analyses of the interaction between Benjamin and the psychotherapist indicate the importance of creating a supportive and secure environment before working with the child's problems. Surprisingly, it seems that CBT adherence was most helpful for Benjamin, while PDT was less helpful. Perhaps the therapist was working through some feelings in her countertransference that allowed her to provide Benjamin with a type of structure that was particularly attuned to him and had a containing function. It seems like Benjamin responded well to structure and not so well to the lack of structure, which made him anxious. In this way the 'CBT-like' work embedded in an overall psychodynamic way of thinking was helpful in this therapy. Working with Problems was in this therapy negatively correlated with feeling words (according to the FWC-24) like warm, free, playful, enthusiastic and relaxed. When adhering to CBT principles, the therapist felt more playful and enthusiastic, and the interaction structure Structured Closeness was more prominent. When adhering to PDT principles the therapist felt less open, relaxed and calm. This could be explained by Benjamin's way of handling situations when in touch with negative emotions. We can see that affective periods are followed by periods when Benjamin lessens his affective expressions in accordance with the problems Benjamin shows of displaying a happy, unaffected surface and having difficulties experiencing and expressing genuine emotions.

The present study indicates that it is possible to notice when theory and practice do not coincide. The analysis also shows that the examined psychotherapy differs considerably when compared to the expert ratings of the prototype of psychodynamic child psychotherapy, which is in line with Gastaud et al. (2015), who relates that successful 
therapy does not always have to follow an imagined prototype. Like an earlier study on child psychotherapy by Ramires, Carvalho, Schmidt, Fiorini, and Goodman (2015), the psychotherapist's explicit interpretation of the transference field is not very prominent, nor is the emphasis of earlier periods in the child's life. A tendency of psychodynamic child psychotherapy has been to shift one's focus from the understanding of conflict material, and hence the psychotherapist's interpretation of content, to dealing with the child's access to mentalization, affect regulation, present relational and emotional difficulties, and the process that takes place between the child and psychotherapist. In the examined therapy, frequent occurrence of these latter aspects is discernible. In Benjamin's therapy the therapist adapts the technique to the specific child and his needs. The therapist's flexibility shows the importance of meta-competence: overarching competencies that psychotherapists need to use to guide any intervention, what interventions to use, and when they are suitable.

The active components of treatment do not necessarily have to be the most prominent ones (Ablon et al., 2011). The CPQ rates suitability and how characteristic an item is within an entire session. This can lead to the instrument being able to describe process, structure and course of psychotherapy, but not the timing and quality of therapists' interventions. The CPQ does not describe facial expression, body language or tone of voice, the therapist's thinking and countertransference or the child's inner feelings which may be fundamental in describing the intersubjectivity of interaction between the therapist and the child (Goodman \& Athey-Lloyd, 2011). The psychotherapist's subjective description of psychotherapy process and FWC can provide a complementary picture from the psychotherapist's subjective experiences and feelings during a psychotherapy session.

\section{Strengths and limitations}

Systematic case studies provide an important picture of the treatment that is not captured in data collected at the group level, since each patient-psychotherapist dyad creates its own unique psychotherapeutic process. A strength of this study is that the psychotherapy, which has been examined in its entirety, took place in a naturalistic setting within ordinary child and adolescent psychiatric care. A mixed-methods approach is also a strength. Video-recorded material can contribute to reliable ratings since the recording can be stopped or studied several times. An independent examiner can make interrater judgments. Video-recording might affect the participants and the psychotherapeutic process per se. In this therapy no such obvious influence was noticed. The material is not filtered through the child or psychotherapist; however, this strength can also be seen as a weakness that can be compensated for by the more subjective measure FWC, and the psychotherapist's answers to the questionnaire about his or her experience of the psychotherapy process. A limitation of the study is that 30 of 40 psychotherapy sessions were CPQ-rated by only one rater. Another limitation is that a case study describes only this one unique case. Generalisations should of course be made with caution.

\section{Conclusions}

This study points to the importance of discussing what can be considered the essential elements of psychodynamic child psychotherapy and how and when they are implemented. It underlines the need for further investigation of the processes in single-case studies. 
The CPQ could potentially be used as an instrument in psychotherapy training. The trainee psychotherapist can notice aspects relating to his or her own behaviour, and relational aspects between the child and him or herself, and can, in addition, reflect on how the therapy correlates with a prototypical form of psychotherapy. It may require a change in the training of new psychotherapists, where an emphasis on the techniques previously seen mostly as common factors becomes part of the curriculum. In combination with a more traditional focus on transference and countertransference psychotherapists in training might strengthen their understanding of the psychotherapeutic process.

The importance of common factors, such as the child's and the psychotherapist's expectations of goals and means, motivation and therapeutic alliance, needs discussion when actual therapy does not coincide with theoretical assumptions of psychotherapy techniques (Goodman et al., 2016). This also might allow light to be shed on unexpected aspects outside the mainstream theory of the therapy process and stimulate interesting questions on the borders of different orientations in psychotherapy. The advantage of including the use of the CPQ in the training of child psychotherapists could also be to help familiarise trainees with process research.

\section{Note}

1. A within-subjects multivariate analysis of variance (MANOVA) is conducted when an investigator wants to analyse whether there are significant differences among multiple variables (e.g., among the three prototype adherence scores) in the same sample (i.e., all the therapy sessions conducted). A pairwise statistical comparison is conducted when an investigator wants to analyse the result of a MANOVA more closely; specifically, whether there is a significant difference between two specific variables (e.g., PDT adherence and CBT adherence).

\section{Acknowledgments}

This study was supported by grants from Clas Groshinsky's memorial foundation. The authors are most grateful to Mimmi Edgren for her work as a co-rater of the CPQ.

\section{Disclosure statement}

No potential conflict of interest was reported by the authors.

\section{Notes on contributors}

Fredrik Odhammar, Ph.D., is a licensed psychologist, licensed psychotherapist and specialist in clinical psychology. He is a teacher, supervisor and Director of Studies at the Erica Foundation in Stockholm, Sweden, an institute providing psychotherapy for children and adolescents, professional training at university level and research. In his own research he has special interest in clinical process and outcome in child psychotherapy. His previous publications have addressed goals set by children, parents and psychotherapists in psychodynamic child psychotherapy, and how therapy outcomes can be related to changes in global functioning.

Geoff Goodman, Ph.D., is Associate Professor of Psychology in the Long Island University Clinical Psychology Doctoral Program, New York. He is also a licensed clinical and school psychologist with 26 years of experience in private practice in New York, treating children and 
adolescents as well as adults. He is certified by the American Board of Professional Psychology (ABPP) and is certified as both an adult and a child and adolescent psychoanalyst and Fellow of the International Psychoanalytical Association (FIPA). Goodman is also Chair of the Child, Adolescent, and Family Therapy Research (CAFTR) Special Interest Group of the Society for Psychotherapy Research.

Gunnar Carlberg, Ph.D., former Professor at the Department of Education, Stockholm University and former Director of the Erica Foundation in Stockholm. He is a licensed psychologist and psychotherapist with various publications within psychodynamic developmental psychology and child and adolescent psychotherapy research.

\section{References}

Ablon, S. J., Levy, R. A., \& Smith-Hansen, L. (2011). The contributions of the Psychotherapy Process Q-Set to psychotherapy research. Research in Psychotherapy, 14(1), 14-48.

American Psychiatric Association. (2000). Diagnostic and statistical manual of mental disorders$I V$. Washington, DC: Author.

Bychkova, T., Hillman, S., Midgley, N., \& Schneider, S. (2011). The psychotherapy process with adolescents: A first pilot study and preliminary comparisons between different therapeutic modalities using the Adolescent Psychotherapy Q. Journal of Child Psychotherapy, 37(3), 327-348.

Carlberg, G. (2010). Focused systematic case studies: An approach linking clinical work and research. In J. Tsiantis \& J. Trowell (Eds.), Assessing change in psychoanalytic psychotherapy of children and adolescents: Today's challenge (pp. 93-113). London: Karnac Books.

Dahl, H.-S. J., Røssberg, J. I., Bøgwald, K. P., Gabbard, G. O., \& Høglend, P. A. (2012). Countertransference feelings in one year of individual therapy: An evaluation of the factor structure in the Feeling Word Checklist-58. Psychotherapy Research, 22(1), 12-25.

Dahl, H.-S. J., Røssberg, J. I., Crits-Christoph, P., Gabbard, G. O., Hersoug, A. G., Perry, J. C., ... Høglend, P. A. (2014). Long-term effects of analysis of the patient-Therapist relationship in the context of patients' personality pathology and therapists' parental feelings. Journal of Consulting and Clinical Psychology, 82(3), 460-471.

Di Lorenzo, M., Maggiolini, A., \& Suigo, V. A. (2015). A developmental perspective on adolescent psychoanalytic psychotherapy. An Italian study with the adolescent Psychotherapy Q-Set. Research in Psychotherapy: Psychopathology, Process and Outcome, 18 (2), 102-113.

Fonagy, P., Steele, M., Moran, G. S., Steel, H., \& Higgit, A. C. (1991). The capacity for understanding mental states: The reflective state in parent and child and its significance for security of attachment. Infant Mental Health Journal, 12(3), 201-218.

Gastaud, M. B., Carvalho, C., Goodman, G., \& Ramires, V. R. R. (2015). Assessing levels of similarity to a "psychodynamic prototype" in psychodynamic psychotherapy with children: A case study approach (preliminary findings). Trends in Psychiatry and Psychotherapy, 37(3), 161-165.

Goodman, G., \& Athey-Lloyd, L. (2011). Interaction structures between a child and two therapists in the psychodynamic treatment of a child with Asperger's disorder. Journal of Child Psychotherapy, 37(3), 311-326.

Goodman, G., Midgley, N., \& Schneider, C. (2016). Expert clinicians' prototypes of an ideal child treatment in psychodynamic and cognitive-behavioral therapy: Is mentalization seen as a common process factor? Psychotherapy Research, 26(5), 590-601.

Goodman, R. (1997). The strength and difficulties questionnaire: A research note. Journal of Child Psychology and Psychiatry, 38(5), 581-586.

Graneheim, U. H., \& Lundman, B. (2004). Qualitative content analysis in nursing research: Concepts, procedure and measures to achieve trustworthiness. Nurse Education Today, 24(2), 105-112. 
Holmqvist, R. (2001). Patterns of consistency and deviation in therapists' countertransference feelings. Journal of Psychotherapy Practice and Research, 10(2), 104-116.

Holmqvist, R., \& Armelius, B. Å. (1996). Sources of therapists' countertransference feelings. Psychotherapy Research, 6(1), 70-78.

Jones, E. E. (2000). Therapeutic action: A guide to psychoanalytic therapy. North Bergen: Bookmart Press.

Kazdin, A. E. (2009). Understanding why psychotherapy leads to change. Psychotherapy Research., 19(4-5), 418-428.

Lundh, A., Kowalski, J., Sundberg, C. J., Gumpert, C., \& Landén, M. (2010). Children's global assessment scale (CGAS) in a naturalistic clinical setting: Inter-rater reliability and comparison with expert ratings. Psychiatry Research, 177, 206-210.

Midgley, N. (2007). Researching the process of psychoanalytic child psychotherapy. In E. Kennedy \& E. Midgley (Eds.), Process and outcome research in child, adolescent and parentinfant psychotherapy: A thematic review (pp. 8-53). North Central London Strategic Health Authority.

Midgley, N., \& Kennedy, E. (2011). Psychodynamic psychotherapy for children and adolescents: A critical review of the evidence base. Journal of Child Psychotherapy, 37(3), 232-260.

Mitchell, S. A., Aron, L., Harris, A., \& Suchet, M. (Eds.). (1999). Relational psychoanalysis. New York: Analytic.

Odhammar, F., \& Carlberg, G. (2015). Parents' and psychotherapists' goals prior to psychodynamic child psychotherapy. European Journal of Psychotherapy \& Counselling, 17 (3), 277-295.

Odhammar, F., Sundin, E., Jonson, M., \& Carlberg, G. (2011). Children in psychodynamic psychotherapy. Changes in global functioning. Journal of Child Psychotherapy, 37(3), 261-279.

Pruetzel-Thomas, A. (2006). Exploring child Psychotherapy Process and Q-Sort methodology. London: Anna Freud Centre.

Ramires, V. R. R., Carvalho, C., Schmidt, F. M. D., Fiorini, G. P., \& Goodman, G. (2015). Interaction structures in the psychodynamic therapy of a boy diagnosed with Asperger's disorder: A singlecase study. Research in Psychotherapy: Psychopathology, Process and Outcome, 18(2), 129-140.

Schneider, C., \& Jones, E. E. (2004). The Child Psychotherapy Q-set coding manual. Unpublished manuscript.

Schneider, C., Midgley, N., \& Duncan, A. (2010). A "motion portrait" of a psychodynamic treatment of an 11-year-old girl: Exploring interrelations of psychotherapy process and outcome using the Child Psychotherapy Q-Set. Journal of Infant, Child, and Adolescent Psychotherapy, 9(2-3), 94-107.

Schneider, C., Pruetzel-Thomas, A., \& Midgley, N. (2009). Discovering new ways of seeing and speaking about psychotherapy process: The Child Psychotherapy Q-set. In N. Midgley, J. Anderson, E. Grainger, T. Nesic-Vuckovic, \& C. Urwin (Eds.), Child psychotherapy and research: New approaches, emerging findings (pp. 72-84). London: Routledge.

Schröder, T., Orlinsky, D., Rønnestad, M. H., \& Willutzki, U. (2015). Psychotherapeutic process from the psychotherapist's perspective. In O. C. G. Gelo, A. Pritz, \& B. Rieken (Eds.), Psychotherapy research: Foundations, process, and outcome; psychotherapy research: Foundations, process, and outcome (pp. 351-365). New York: Springer-Verlag.

Shaffer, D., Gould., M. S., Brasic, J., Ambrosini, P. A., Bird, H., \& Aluwahlia, S. (1983). A children's global assessment scale (CGAS). Archives of General Psychiatry, 11(40), 1228-1231.

Svendsen, B., \& Hansen, B. R. (2008). The emergent helper - Steps in the early phase of alliance formation with children. Matrix, 25(4), 297-322. 